\title{
Research on Hysteresis-band Current Tracking Strategy for Modular Multilevel Converter in DG System
}

\author{
Yu Ji, Jun Mei, Xiaozhou Du, Tian Ma, Jianyong Zheng \\ Department of Electrical Engineering, Southeast University, NanJing, 210096, China
}

\begin{abstract}
Modular multilevel converter(MMC) can be used in DG system. The double closed-loop control strategy including dc bus voltage outer loop and current inner loop is adopted in the control system, which makes dc bus voltage stable even when active power changes. The current inner loop has a new control strategy which is hysteresis-band current tracking control. By real-time monitoring the voltage of the grid and the deviation between the output current and the given current, the input submodules' number of upper/lower arm is determined. Monitoring the direction of current in one arm and comparing the voltage of submodules, then changing the working states of real submodules, the voltages of the upper/lower arm's capacitors can be well balanced. The validity of the proposed method is verified by simulation and experimental results of five-level prototype of MMC.
\end{abstract}

Keywords- Modular multilevel converter(MMC); DG system; Dc bus voltage; Hysteresis-band current tracking control; Voltage balancing control.

\section{INTRODUCTION}

In recent years, besides the conventional energy sources, the small scale distributed generation of power from renewable energy sources has drawn plenty of attention. Distributed Energy Resources need additional infrastructure and inverter to connect them to the grid. Modular multilevel converter (MMC) which was proposed by Marquardt and Lesnicar in Germany has attracted many researchers recently. MMC is composed of several submodules and has a common de bus which has advantage in HVDC system and distributed generation. The output power of distributed generation is not very stable because of the fluctuation and intermittent output. The double closed-loop control strategy is based on dc bus voltage outer loop and currents inner loop. Dc bus voltage is stable when the active power changes. The currents inner loop has a new control strategy which is hysteresis-band current tracking control. The proposed control strategy is simple and reliable. The validity of the proposed method is verified by the simulation results and experimental results of five-level prototype of MMC.

\section{SYSTEM STRUCTURE}

Fig. 1 shows the structure of DG system. Photovoltaic/fuel power system and wind power system can operate in parallel where the converter must be MMC.

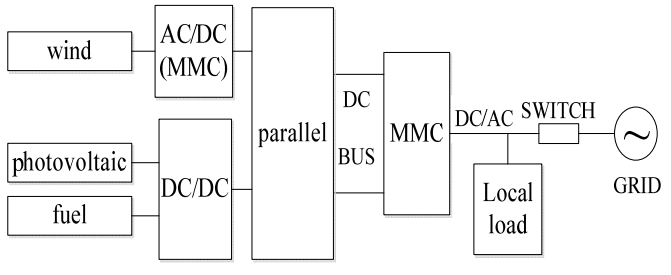

Figure 1. Structure of DG system

Fig. 2 shows the three-phase equivalent circuit of the MMC, which has two arms including the upper arm and the lower arm, with each arm having n submodules (SM), one equivalent resistor $\mathrm{R}$ and buffer inductor $\mathrm{L} . \mathrm{L}_{\mathrm{s}}$ is the ac-link inductor which connect MMC to grid/load. The SM is composed of one capacitance and two switches.

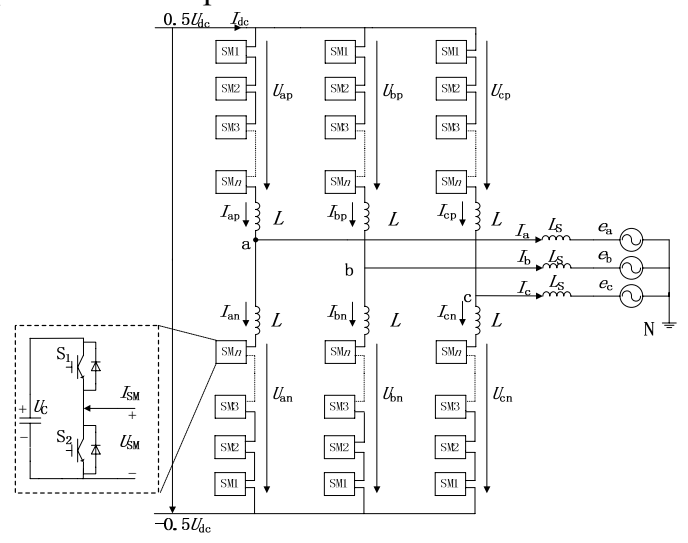

Figure 2. Three-phase equivalent circuit of MMC

The working states of SM are shown in Table I. The output voltage of $\mathrm{SM}$ is " $\mathrm{U}_{\mathrm{C}}$ " or " 0 " according to the current $I_{S M}$ direction and the status of two switches. The capacitance of SM has three status. For example, if $\mathrm{I}_{\mathrm{SM}}>0$, the capacitor would be charged, and if $\mathrm{I}_{\mathrm{SM}}<0$, the capacitor would be discharged. The capacitor voltage will be kept while the SM is "OFF."

TABLE I. HALF-BRIDGE SUBMODULE WORKING STATES

\begin{tabular}{cccccc}
\hline mode & $\mathrm{S}_{1}$ & $\mathrm{~S}_{2}$ & $I_{\mathrm{SM}}$ & $U_{\mathrm{SM}}$ & capacitor \\
\hline 1 & 1 & 0 & $>0$ & $U_{\mathrm{C}}$ & charging \\
\hline 2 & 1 & 0 & $<0$ & $U_{\mathrm{C}}$ & discharging \\
\hline 3 & 0 & 1 & $>0$ & 0 & bypass \\
\hline 4 & 0 & 1 & $<0$ & 0 & bypass \\
\hline
\end{tabular}

III. BASIC STRUCTURE AND CONTROL

From Fig.2, output current $i_{j}$ and output power $P_{j}$ can be expressed as following $(i=a, b, c)$ : 


$$
\left\{\begin{array}{l}
P_{a}=i_{a} \cdot e_{a} \\
P_{b}=i_{b} \cdot e_{b} \\
P_{c}=i_{c} \cdot e_{c}
\end{array}\right.
$$

$I_{j}$ represents the current of $j$ phase, $e_{j}$ represents the voltage of $j$ phase, $P_{j}$ represents the power of $j$ phase.

Using Park transformation to (1), we obtain:

$$
\left\{\begin{array}{l}
P=e_{d} I_{d}=U_{d c} I_{d c} \\
Q=-e_{d} I_{q}
\end{array}\right.
$$

$\mathrm{P}$ represents the total active power, while $\mathrm{Q}$ represents the total reactive power. So, we obtain the double closed-loop control strategy based on dc bus voltage outer loop and currents inner loop which is seen in Fig.3. In comparison with the traditional PI control strategy, the new strategy is simple and reliable.

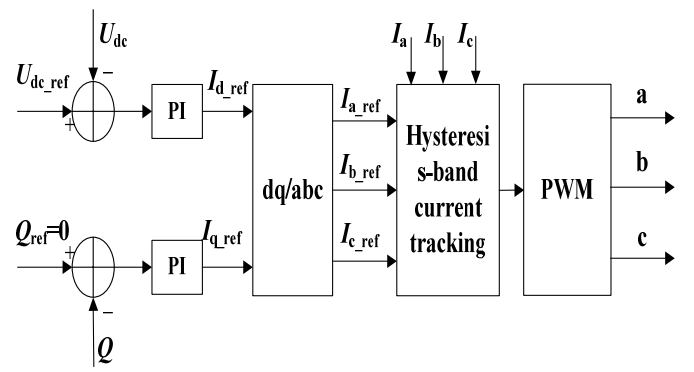

Figure 3. The grid-connected Strategy of hysteresis-band current tracking control

\section{N+1 HYSTERESIS-BAND CURRENT TRACKING LEVEL STRATEGY}

The system is symmetrical. Just taking a phase as an example, the upper and lower arm's voltage can be expressed as followings:

$$
\begin{gathered}
\frac{U_{d c}}{2}-U_{a o}=U_{a p}+L \frac{d I_{a p}}{d t} \\
\frac{U_{d c}}{2}+U_{a o}=U_{a n}+L \frac{d I_{a n}}{d t} \\
I_{a p}=I_{a n}+I_{a} \\
U_{a o}=L_{s} \frac{d I_{a}}{d t}+e_{a}
\end{gathered}
$$

From (3)-(6), we obtain:

$$
\left\{\begin{array}{l}
L_{a}=L_{s}+\frac{L}{2} \\
U_{d a o}=\frac{1}{2}\left(U_{a n}-U_{a p}\right) \\
L_{a} \frac{d I_{a}}{d t}=U_{d a o}-e_{a} \\
U_{A O}=U_{d a o}-e_{a}
\end{array}\right.
$$

$\mathrm{L}_{\mathrm{a}}$ is equivalent inductance, $\mathrm{U}_{\text {dao }}$ is equivalent output voltage, $e_{\mathrm{a}}$ is the voltage of grid/load. $\mathrm{U}_{\mathrm{AO}}$ is the deviation between $e_{\mathrm{a}}$ and $\mathrm{U}_{\mathrm{dao}}$.
If $\mathrm{U}_{\mathrm{AO}}<0$, the output current $\mathrm{I}_{\mathrm{a}}$ decreases. If $\mathrm{U}_{\mathrm{AO}}>0, \mathrm{I}_{\mathrm{a}}$ increases. Fig. 4 shows the principle drawing of hysteresis-band current tracking control.

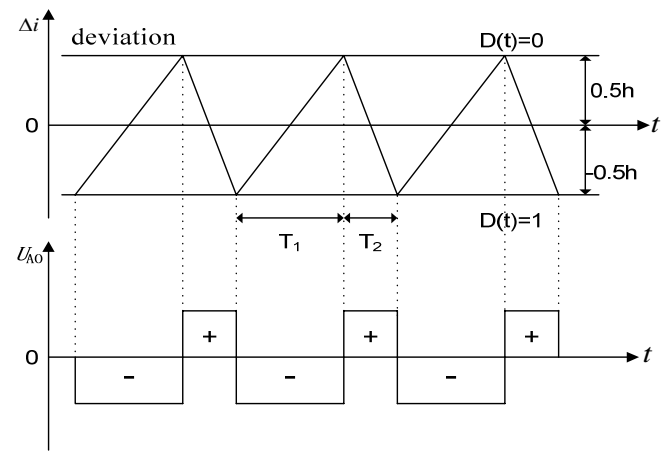

Figure 4. Principle drawing of hysteresis-band current tracking control

The intervals of the load/grid voltage is seen in Fig.5

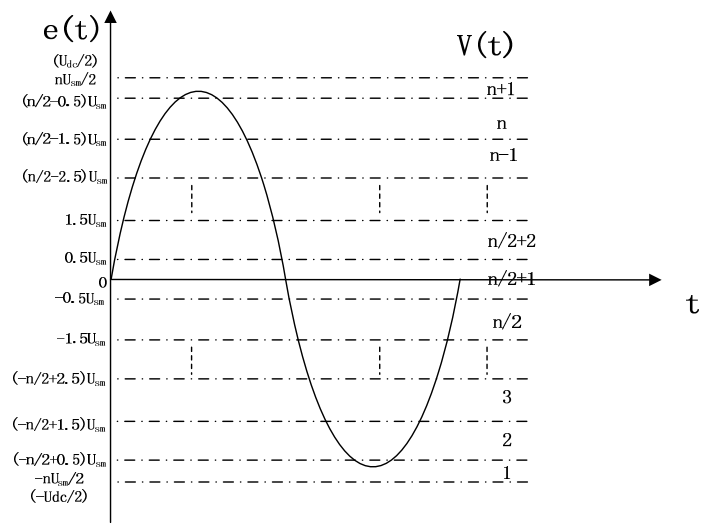

Figure 5. The intervals of load voltage

From Fig 5 , we can see that there is $\mathrm{n}+1$ intervals of load voltage. In order to suppress circulating-current, we adopt $\mathrm{n}+1$ level strategy, then $\mathrm{U}_{\mathrm{dao}}$ and SM voltage $\mathrm{U}_{\mathrm{sm}}$ can be expressed as followings:

$$
\left\{\begin{array}{l}
U_{s m}=\frac{U_{d c}}{n} \\
U_{d a o}(t)=\left[N_{n}(t)-0.5 n\right] \cdot U_{s m}
\end{array}\right.
$$

$\mathrm{N}_{\mathrm{n}}(\mathrm{t})$ is the sum of the input lower SM. From Fig4 and Fig5, we ensure that if $\mathrm{D}(\mathrm{t})=1, \mathrm{U}_{\mathrm{dao}}(\mathrm{t})>\mathrm{e}_{\mathrm{a}}(\mathrm{t})$.If $\mathrm{D}(\mathrm{t})=0$, $\mathrm{U}_{\text {dao }}(\mathrm{t})<\mathrm{e}_{\mathrm{a}}(\mathrm{t})$. So, we can obtain the $\mathrm{N}_{\mathrm{n}}(\mathrm{t})$ and the sum of the input upper $\mathrm{SM} \mathrm{N}_{\mathrm{p}}(\mathrm{t})$ :

$$
\begin{cases}N_{n}(t)= \begin{cases}0 & 2 D(t)+V(t)-2=-1 \\ 2 D(t)+V(t)-2 & 0 \leq 2 D(t)+V(t)-2 \leq n \\ n & 2 D(t)+V(t)-2=n+1\end{cases} \\ N_{p}(t)=n-N_{n}(t) & \end{cases}
$$

In summary, The current inner loop has a new control strategy which is hysteresis-band current tracking control. By real-time monitoring the voltage of 
the grid and the deviation between the output current and the given current, the input SM number of upper/lower arm is determined, then the output current can track the given current quickly and stably.

\section{V.CAPACITOR VOLTAGE BALANCE CONTROL}

From Tab.1, there are three modes of submodule capacitor working states:" charging", "discharging" and "bypass", which is due to the arm current direction and the status of the two switches. Capacitor voltage balance is very important in MMC. We can obtain the strategy of voltage balance control: Monitoring the direction of current in one arm and comparing the voltages of submodules, then changing the working states of real submodules, the voltages of the upper/lower arm's capacitors can be well balanced.

Assume that $\mathrm{n}$ is equal to 4 ,we can see there are 4 submodules in the upper/lower arm. If we find $\mathrm{U}_{1}>\mathrm{U}_{2}>\mathrm{U}_{3}>\mathrm{U}_{4}$, the mapping relationships must be changed.

TABLE II. THE WORKING STATES OF SUBMODULE

\begin{tabular}{ccccc}
\hline mode & \multicolumn{2}{c}{$\mathrm{I}_{\mathrm{p}}(\mathrm{t}) / \mathrm{I}_{\mathrm{n}}(\mathrm{t}) \geq 0$} & \multicolumn{2}{c}{$\mathrm{I}_{\mathrm{p}}(\mathrm{t}) / \mathrm{I}_{\mathrm{n}}(\mathrm{t})<0$} \\
\hline $\mathrm{N}_{\mathrm{p}}(\mathrm{t}) / \mathrm{N}_{\mathrm{n}}(\mathrm{t})$ & charging & bypass & discharging & bypass \\
\hline 0 & none & $1,2,3,4$ & none & $1,2,3,4$ \\
\hline 1 & 4 & $1,2,3$ & 1 & $2,3,4$ \\
\hline 2 & 3,4 & 1,2 & 1,2 & 3,4 \\
\hline 3 & $2,3,4$ & 1 & $1,2,3$ & 4 \\
\hline 4 & $1,2,3,4$ & none & $1,2,3,4$ & none \\
\hline
\end{tabular}

Tab. 2 shows the working states of submodule, we can obtain that: SM1 is the easiest discharging submodule and the hardest charging submodule while SM4 is the hardest discharging submodule and the easiest charging submodule. Therefore, the voltage of SM1 will decrease while the voltage of SM4 will increase. After several cycles, capacitor voltage balance will come true.

\section{SIMULATION AND EXPERIMENT}

\section{A. Simulation}

In order to verify the validity of the analyses, we build simulation model in matlab/simulink. The simulation parameters are seen inTab.3.The simulation waveforms are seen in Fig.6.

TABLE III. THE SIMULATION PARAMETERS

\begin{tabular}{cc}
\hline Parameters & Values \\
\hline No.of Submodules in each arm & 4 \\
\hline Submodule Capacitor C & $4700 \mathrm{uF}$ \\
\hline Arm Equivalent Resistance & $0.1 \Omega$ \\
\hline Arm Inductor L & $1.2 \mathrm{mH}$ \\
\hline AC Link Inductor $\mathrm{L}_{\mathrm{s}}$ & $8 \mathrm{mH}$ \\
\hline DC Bus Voltage $\mathrm{U}_{\mathrm{dc}}$ & $800 \mathrm{~V}$ \\
\hline
\end{tabular}

\begin{tabular}{cc}
\hline $\mathrm{h}$ & $0.04 \mathrm{~A}$ \\
\hline AC system voltage $\mathrm{U}_{\mathrm{s}}(\mathrm{rms})$ & $220 \mathrm{~V}$ \\
\hline Active power & $18 \mathrm{~kW} 27 \mathrm{~kW}$ \\
\hline Power frequency & $50 \mathrm{~Hz}$ \\
\hline
\end{tabular}
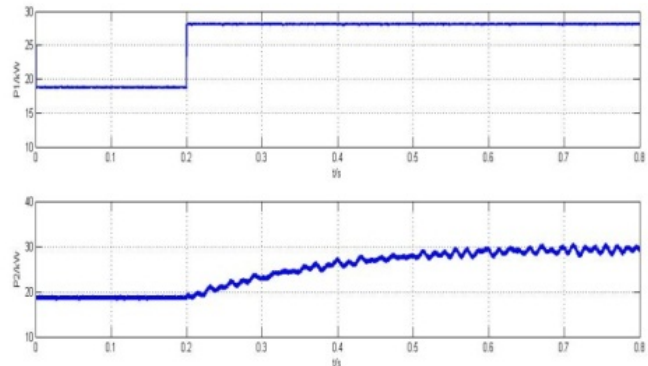

(a)

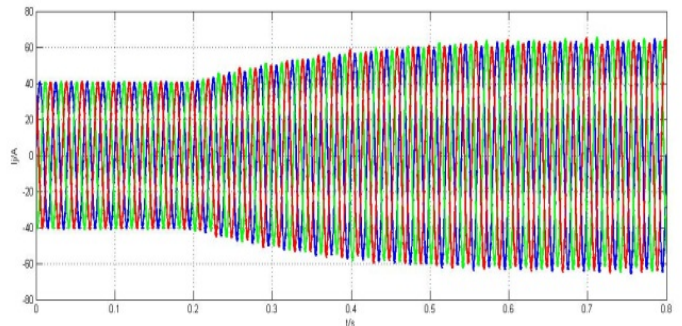

(b)

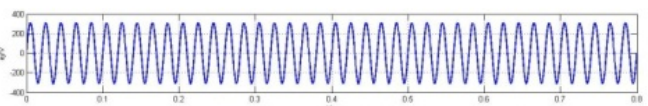

Trummum

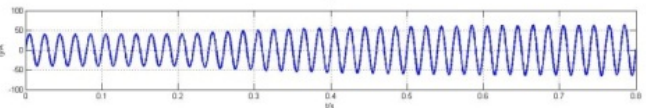

(c)

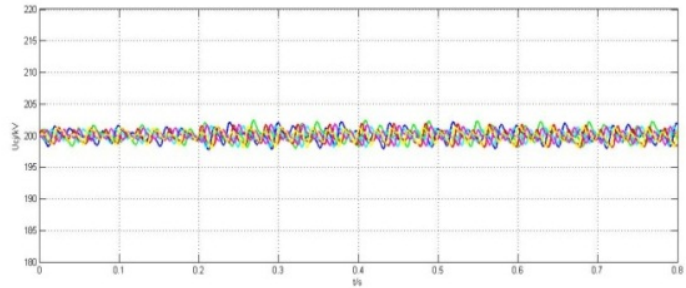

(d)

Figure 6 . The simulation waveforms of hysteresis-band current tracking control

From Fig6(a), We can see the change of absorbing and producing active power. The absorbing active power increases from $18 \mathrm{~kW}$ to $27 \mathrm{~kW}$, then the producing active power will increase accordingly. Fig6(b) shows the output current of three-phases. The current increases quickly after $0.2 \mathrm{~s}$ which is symmetrical. Fig6(c) shows the grid voltage, output voltage and output current of a single phase. We can 
find that the output current can track the given current smoothly. Fig6(d) shows the voltages of SMs, the voltages of the upper/lower arm's capacitors can be well balanced.

\section{B. Experiment}

The experimental parameters are the same as Tab.3, waveforms are shown in Fig.7.

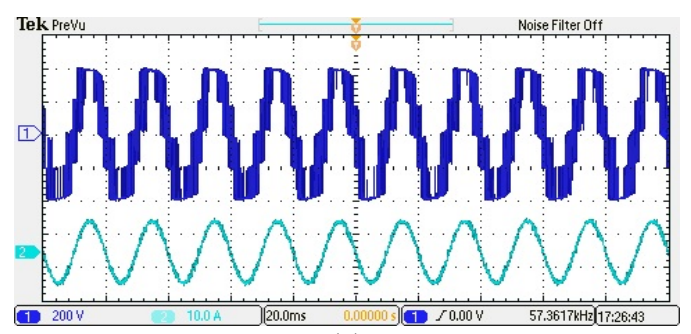

(a)

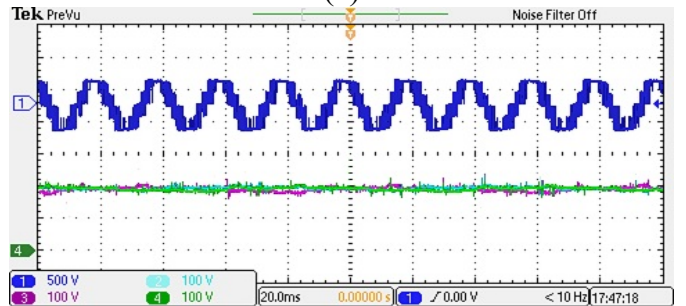

(b)

Figure 7. Experimental waveforms

Fig7(a) shows the output current and output voltage, we can see that they have the same phase, the voltage of the dc bus is $800 \mathrm{~V}$ which is stable. Fig7(b) shows the voltages of
SMs, the voltages of the upper/lower arm's capacitors can be well balanced.

\section{CONCLUSIONS}

In this paper, Hysteresis-band Current Tracking Strategy for modular multilevel converter in distributed generation is introduced. The output current can track the given current smoothly and the voltages of the upper/lower arm's capacitors can be well balanced. The proposed strategy is simple and reliable for control which has great promise.

\section{REFERENCES}

[1] B.N.Alajmi, KH Ahmed, GP Adam, S.J.Finney, and B.W.Williams. Modular multilevel inverter with maximum power point tracking for grid connected photovoltaic application[J].IEEE International Symposium on Industrial Electronics,2011,22(6):2057-2062

[2] S.Rajasekar and R.Gupta. Solar photovoltaic power conversion using modular multilevel converter[J]. Students Conference on Engineering and Systems, 2012,1(1): 1-6

[3] Gu Herong,Yang Zilong, Wu Weiyang. Research on Hysteresis-band Current tracking Control of Grid-connected Inverter[J]. Proceedings of the CSEE,2006,26(9):108-112

[4] Hong Feng,Shan Renzhong, Wang Huizhen, Yan Yangguang.A Varied Hysteresis-Band Current Controller With Fixed Switching Frequency [J].Transactions of China Electrotechnical Society,2009,24(1):115-119

[5] Zou Chao,Wang Ben,Li Tai.Control strategy of VSC-HVDC system supplying power for passive networks[J].Power System Technology, 2009,33(2):84-88

[6] M. Guan and Z. Xu. Modeling and control of a modular multilevel converter-based HVDC system under unbalanced grid conditions[J].IEEE Transactions on Power Electronics,2012,27(12): 4858-4867 